\title{
Reduced short-term thermic effects of a meal in obese adolescent girls
}

\author{
Victor L. Katch, Catherine P. Moorehead, M. Daniel Becque*, and Albert P. Rocchini** \\ Behnke Laboratory for Body Composition Research, Department of Movement Science, Division of Kinesiology, and Section of \\ Pediatric Cardiology, School of Medicine, 401 Washtenaw Ave. CCRB, The University of Michigan, Ann Arbor, MI 48109, USA
}

Accepted July 7, 1992

Summary. Post-meal energy expenditure (TEM) was compared for 14 healthy obese (body fat $=45.3 \%$, body mass index, $\mathrm{BMI}=35.9 \mathrm{~kg} \mathrm{~m}^{-2}$ ) and 9 healthy nonobese (body $\mathrm{fat}=20.7 \%$, BMI $=17.8 \mathrm{~kg} \mathrm{~m}^{-2}$ ) adolescent girls. The test meal for both groups was a standard $3348.8-\mathrm{kJ}$, 0.473-1 chocolate milkshake of $15 \%$ protein (casein), $40 \%$ fat (polyunsaturated/saturated ratio $=0.05 ; 75 \mathrm{mg}$ cholesterol) and $45 \%$ carbohydrate (lactose and sucrose). Glucose, insulin and resting energy expenditure (RMR) were measured at rest prior to meal consumption and $20,40,60,90$, and 120 min after the meal. Cumulative net TEM was calculated as the integrated area under the TEM curve with RMR as baseline. Reliability was assessed by retesting 4 subjects, and a placebo effect was tested by administering a flavored energy-free drink. Results indicated high reliability and no placebo effect. The meal resulted in a greater rise in insulin and glucose for the obese compared to the nonobese subjects $(P \leqslant 0.05)$, and a significant TEM for both groups $(P \leqslant 0.05)$. The cumulative TEM ( $\left.\mathrm{W} \mathrm{kg}^{-1}\right)$ was $61.9 \%$ greater for the nonobese $(P<0.01)$ when expressed relative to body mass, and $33.2 \%$ greater for the nonobese $(P \leqslant 0.01)$ when expressed relative to the fat-free body mass. Expressed relative to the meal, the TEM was $25.5 \%$ less for the obese $(P<0.01)$. The data support an energy conservation hypothesis for obese female adolescents.

Key words: Diet - Induced thermogenesis - Thermic effect of food - Energy expenditure - Obesity - Adolescents - Body composition - Children - Energy

\footnotetext{
* Present address: Department of Physical Education, Southern Illinois University, Carbondale, IL 62901, USA

** Present address: Division of Pediatric Cardiobiology, Variety Club Children's Hospital, Box 94, University of Minnesota Medical School, Minneapolis, MN 55455, USA
}

Correspondence to: V. Katch

\section{Introduction}

There are few studies comparing basal or resting (resting metabolic rate; RMR) metabolism of obese and nonobese adolescents (Bauer and Blunt 1924; Beirring 1919; Blunt et al. 1921; Boothby et al. 1936; Griffiths and Payne 1976; Harris and Benedict 1919; Waxman and Stunkard 1980), and only three (Bandini et al. 1989; Epstein et al. 1987; Molnar et al. 1985) have compared the thermic response to a meal (TEM).

Molnar et al. (1985) investigated the TEM of 7 nonobese and 11 obese children (age range $=7-15$ years) after a meal that provided $60.3 \mathrm{~kJ}$ (kg fat-free body mass) ${ }^{-1}$ in the form of bread, egg and milk (protein $=24 \%$, fat $=38 \%$ and carbohydrate $=38 \%$ ). The results revealed a nonsignificant increase in TEM (indexed to fat-free body mass) for early-onset obese children compared to age-matched nonobese children, expressed relative to energy intake. However, 4 children with lateonset obesity had significantly lower TEM and insulin responses than the control and 7 overweight children with early-onset obesity. It was concluded that TEM was reduced in early-phase childhood obesity and increased in late-phase obesity, when hyperinsulinemia had developed.

Epstein et al. (1987) reported that the TEM response of 17 obese 8 - to 12 -year-olds to a liquid meal $(20 \mathrm{~kJ} \mathrm{~kg}$ body mass $^{-1}$ ) was not different from the TEM of 15 nonobese 8- to 12-year-olds, expressed relative to energy intake.

In the third study, Bandini et al. (1989) studied the TEM of 7 obese and 6 nonobese 12- to 19-year-olds during isocaloric and hypercaloric conditions. In this very comprehensive study, it was found that TEM was similar and did not change significantly during overfeeding for the obese and nonobese subjects.

Thus, the limited data on adolescent do not support an energy conservation hypothesis with respect to TEM, as reported in numerous studies on adults (Jequier et al. 1987; Jung et al. 1979; Kaplan and Leveille 1976; Segal and Gutin 1983; Segal et al. 1985, 1990; Shetty et al. 1981). 
Table 1. Descriptive data of subjects: mean (SE)

\begin{tabular}{lcllll}
\hline Variable & $\begin{array}{l}\text { Obese } \\
n=14\end{array}$ & $\begin{array}{l}\text { Nonobese } \\
n=9\end{array}$ & $\begin{array}{l}\text { Signif- } \\
\text { icance }\end{array}$ \\
\hline Age (years) & 14.0 & $(0.7)$ & 14.0 & $(0.9)$ & NS \\
Stature (m) & $1.569(0.024)$ & $1.580(0.022)$ & NS \\
Body mass (kg) & $88.29(9.0)$ & 43.82 & $(2.3)$ & $P \leqslant 0.01$ \\
Fat-free mass (kg) & $45.35(3.1)$ & $34.76(1.9)$ & $P \leqslant 0.01$ \\
Fat (\%) & 46.7 & $(1.9)$ & 20.7 & $(1.2)$ & $P \leqslant 0.01$ \\
BSA $^{a}\left(m^{2}\right)$ & $1.885(0.07)$ & $1.406(0.03)$ & $P \leqslant 0.01$ \\
BMI $^{2}\left(\mathrm{~kg} \mathrm{~m}^{-2}\right)$ & $35.86(1.2)$ & $17.78(0.6)$ & $P \leqslant 0.01$ \\
\hline
\end{tabular}

a BSA, body surface area; BMI, body mass index

In light of the limited data on TEM of adolescents we decided to investigate TEM differences further between obese and nonobese adolescent girls.

\section{Methods}

Testing was performed in the Clinical Research Unit of the University Hospital. Fourteen healthy obese and 9 healthy nonobese girls served as subjects. Descriptive data are presented in Table 1. All of the girls were normally menstruating. Subjects were participants in a larger study examining the physiological aspects of adolescent obesity. Results of these studies have been published elsewhere (Becque et al. 1987, 1988; Katch et al. 1985, 1988a, b, 1990; Rocchini et al. 1987, 1988a).

Body mass $\left(m_{\mathrm{b}}\right)$ and physical activity levels were stable for at least 6 weeks prior to testing. Obesity was defined as $m_{\mathrm{b}}$ for height at a given age greater than the 85 th percentile relative to the Hanes II data (NCHS 1984), and triceps skinfold and percentage body fat $(\% \mathrm{BF})$ greater than $+2 \mathrm{SD}$ units above the age-indexed norm (NCHS 1984). For the nonobese subjects, $m_{b}$ for height was less than the 50th percentile, and the mean percentage body fat equal to or below the age-indexed 50th percentile. Signed informed consent statements were obtained prior to participation.

Height was measured using a stadiometer to the nearest $0.001 \mathrm{~m}$ without shoes, $m_{\mathrm{b}}$ was measured with a beam balance to the nearest $0.01 \mathrm{~kg}$, and total body volume was assessed at residual lung volume by the hydrostatic weighing procedure (Katch et al. 1967). Residual lung volume was measured out of water using a closed-circuit oxygen-dilution method (Wilmore 1969) while the subject was seated in a position similar to that for underwater weighing. Two trials were conducted $(r=0.94)$ and the average used in all calculations. Percentage body fat was calculated from body density using the Siri equation (Siri 1956). Fat-free mass $\left(m_{\mathrm{FF}}\right)$ was determined by subtraction $\left[m_{\mathrm{FF}}=m_{\mathrm{b}}-\left(m_{\mathrm{b}} \times \% \mathrm{BF}\right)\right]$. The standard deviation of replicate trials for the measurement of body density $(n=25$ obese adolescents) was $0.0025 \mathrm{~g} / \mathrm{ml}(2 \% \mathrm{BF})$ $(r=0.96)$.

Oxygen uptake $\left(\mathrm{VO}_{2}\right)$ was measured by open-circuit spirometry. Expired air was collected using a tightly fitting face mask and a meteorological balloon collection system (Katch et al. 1985). The respiratory gases were analyzed with a zirconia cell oxygen analyzer (Applied Electrochemistry) and an infrared carbon dioxide monitor (Beckman Instruments). The analyzers were calibrated before and after each test with gas samples analyzed with the MicroScholander chemical gas apparatus (Scholander 1947). The reproducibility of measuring $V \mathrm{O}_{2}$ was $\pm 2.0 \% ; r=0.97$.

Fasting RMR was assessed in the lying position between 0700 hours and 0800 hours. Immediately afterwards, and after voiding, a $3348.8-\mathrm{kJ}, 0.473-1$ chocolate milkshake was consumed. The drink composition was established as being $15 \%$ protein, $40 \%$ fat and $45 \%$ carbohydrate such that the energy content was known and constant. The protein was primarily from casein and the fat was primarily saturated (polyunsaturated/saturated fatty acids $=0.05$ ), with $75 \mathrm{mg}$ cholesterol. The carbohydrate was from both lactose and sucrose with no complex sources, and contained $700 \mathrm{mg}$ calcium. The drink was consumed within $15 \mathrm{~min}$.

After the initial fasting RMR had been determined an 18-gauge butterfly needle catheter with a two-way stopcock was inserted into a surface vein on the back of the hand. The catheter was kept patent by a slow infusion of heparinized saline solution. Plasma immunoreactive insulin was collected in $2-\mathrm{ml}$ heparinized tubes and assayed using an adaptation of the iodination technique (Berson et al. 1964). Additionally, $2 \mathrm{ml}$ plasma was collected and analyzed for glucose (Hugget and Nixon 1957) via a Beckman glucose analyzer (Beckman Instruments Inc., Fullerton, Calif., USA). The integrated areas under the glucose and insulin curves were calculated. The timing of blood sampling coincided with the $\mathrm{VO}_{2}$ measurements.

$V \mathrm{O}_{2}$ was assessed after the meal with the subject fully reclined. A 10-min expired-air sample was collected during rest (RMR) and at $20,40,60,90$, and 120 min following meal ingestion. It was acknowledged at the outset that $120 \mathrm{~min}$ would be insufficient for the $V \mathrm{O}_{2}$ values to return fully to the pre-meal baseline. However, preliminary data from our laboratory as well as data from other studies (Segal 1990; Segal and Gutin 1983; Segal et al. 1985) suggest that group differences (obese versus nonobese) in $\mathrm{VO}_{2}$ can be determined within $120 \mathrm{~min}$. Of course, a longer post-meal collection period would be necessary to describe the total TEM quantitatively response.

$V \mathrm{O}_{2}$ was converted to an estimate of energy expenditure using the respiratory exchange ratio conversion (Carpenter 1939) and expressed as $\mathrm{W}\left(\mathrm{kJ} \mathrm{s}^{-1}\right)$, and relative to body mass ( $\mathrm{W} \mathrm{kg}_{\mathrm{BM}}^{-1}$ ), fatfree mass ( $\left.\mathrm{W} \mathrm{kg}_{\mathrm{FF}}^{-1}\right)$, and body surface area $\left(\mathrm{W} \mathrm{m}^{-2}\right)$.

The net cumulative post-meal energy expenditure $\left(\mathrm{TEM}_{\text {net }}\right)$ in kilojoules was calculated as the integrated area under the TEM curve using the pre-meal RMR as baseline. The TEM data are presented as the cumulative $\mathrm{TEM}_{\text {net }}$ and expressed as a percentage of the energy value $(\mathrm{kJ})$ of the meal (TEM/meal).

The consistency of the TEM was determined by resting 4 obese subjects following a 1 -week period, and a placebo effect was assessed by administering a flavored energy-free water drink of equal volume on a separate day to 4 different obese subjects.

Comparisons of the differences between obese and nonobese subjects, placebo and meal, and test and retest were made by independent $t$-tests with the Bonferoni multiple-comparison method (McNemar 1969). Regression analysis was used to investigate the relationship between RMR and different estimates of metabolic size. In all cases the level of significance was set at $P \leqslant 0.05$.

\section{Results}

Figure 1 presents the premeal fasting RMR. For the obese, RMR (W) was elevated by $25 \%$ compared to the level in the nonobese $(P \leqslant 0.01)$. In contrast, when expressed as $\mathrm{W} \mathrm{kg}_{\mathrm{BM}}^{-1}$ it was depressed by $40 \%$ compared to the nonobese level $(P \leqslant 0.01)$, and when expressed as $\mathrm{W} \mathrm{kg}_{\mathrm{FF}}^{-1}$ and $\mathrm{W} \mathrm{m}^{-2}$ there were no significant differences between the results in obese and nonobese subjects.

The relationship between fasting RMR (W) and parameters of metabolic size for all subjects is presented in Table 2. Linear relationships were observed for both groups for $m_{\mathrm{b}}(r=0.81)$, fat mass $(r=0.79)$ and fat-free mass $(r=0.75)$. Body mass accounted for the greatest variance $\left(r^{2}\right)$ in RMR $(66 \%)$, followed by fat mass $(62 \%)$, and fat-free mass $(56 \%)$. The correlation with stature was low $(r=0.24, \mathrm{NS})$.

Pre-meal fasting glucose and insulin were comparable for the nonobese and obese (Fig. 2). The meal resulted 

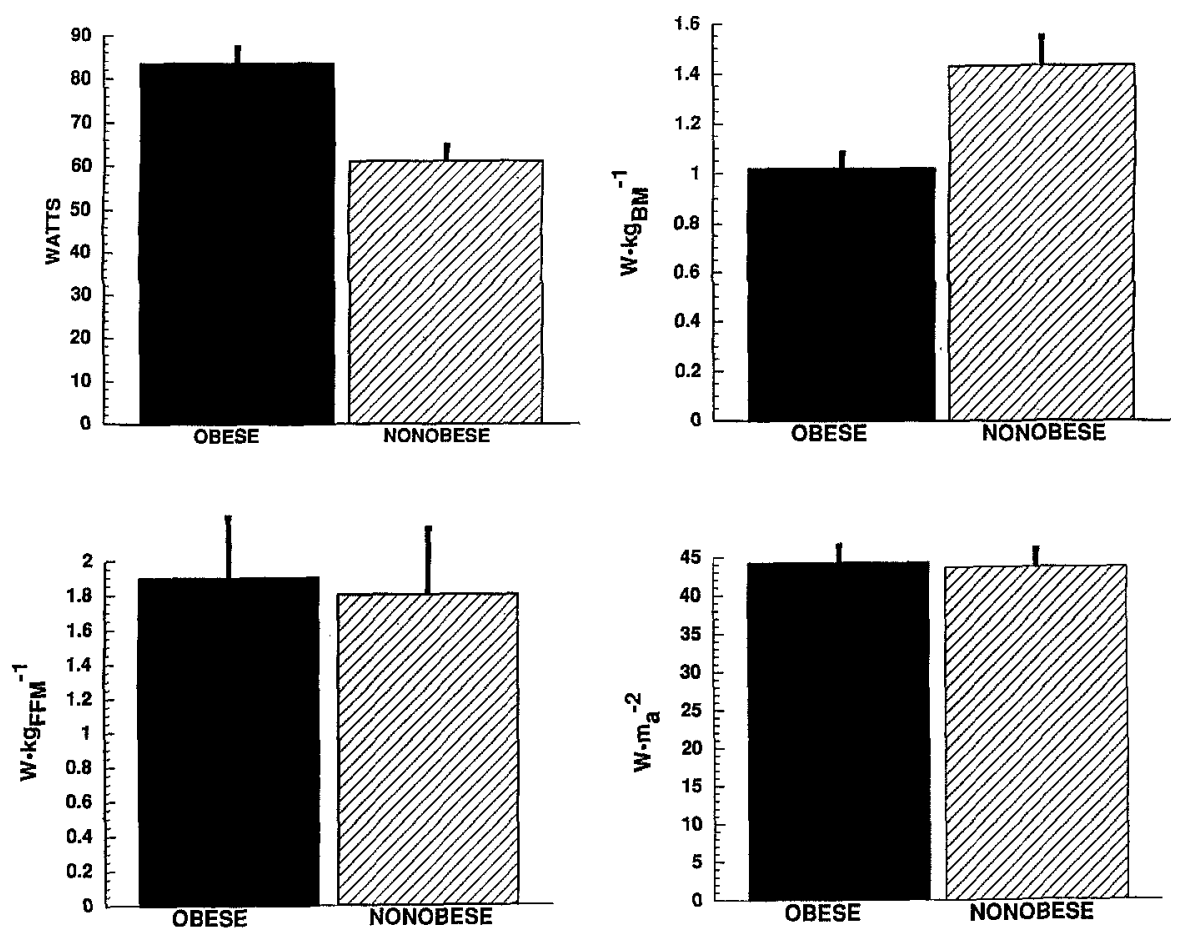

Fig. 1. Comparisons of fasting resting metabolic rate in obese and nonobese female adolescent subjects expressed in absolute terms and referenced to various indices

Table 2. Relationship between fasting resting metabolic rate (W) and parameters of metabolic size for all subjects

\begin{tabular}{lll}
\hline Variable & Correlation & Significance \\
\hline Body mass & 0.81 & 0.01 \\
Fat-free mass & 0.75 & 0.01 \\
Fat mass & 0.79 & 0.01 \\
Height & 0.24 & NS \\
BSA $^{\mathrm{a}}$ & 0.26 & NS \\
\hline
\end{tabular}

${ }^{a}$ BSA, body surface area

in large increases in insulin for both groups, although the rise in insulin was greater in the obese compared to the nonobese subjects $(P \leqslant 0.01)$. The peak insulin for the obese $(90 \%$ above rest, $P \leqslant 0.01)$ was reached $20 \mathrm{~min}$ after the meal. By $120 \mathrm{~min}$, insulin was still elevated by $84 \%(P \leqslant 0.01)$. For the nonobese subjects the peak insulin was $83 \%(P \leqslant 0.01)$ above fasting levels 20 min after the meal. At $120 \mathrm{~min}$, insulin was still $54 \%(P \leqslant 0.01)$ above fasting levels.

For the obese subjects the peak rise in glucose of $28 \%$ above fasting $(P \leqslant 0.05)$ was reached $20 \mathrm{~min}$ after the meal (Fig. 2). By $120 \mathrm{~min}$, it was $19.6 \%$ above fasting $(P \leqslant 0.05)$. For the nonobese subjects, the glucose was little affected by the meal; at $20 \mathrm{~min}$ it was only $12.5 \%$ above fasting levels (NS).

The meal resulted in an increased TEM (W) for both the obese and nonobese girls (Fig. 3). For the obese, TEM peaked at $40 \mathrm{~min}$ at $22 \%$ above the fasting value $(P \leqslant 0.01)$. It stayed elevated throughout the 120 -min collection period. The TEM for the nonobese girls also peaked at $40 \mathrm{~min}$ at a value $29 \%$ greater than the fasting RMR $(P \leqslant 0.01)$. As with the obese, the nonobese subject's TEM stayed elevated throughout the 120-min col- lection period. Also shown in Fig. 3 is the post-meal placebo effect (NS).

As expected, the 120-min post-meal collection period was not long enough for the post-meal energy expenditure to return to baseline (Fig. 3). It is possible to calculate how long it would have taken for the TEM to reach baseline, using exponential analyses; $90 \%$ of the total TEM would have been obtained with an additional $2 \mathrm{~h}$ data collection, and $99 \%$ with an additional $5 \mathrm{~h}$. For the obese subjects the rate of TEM rise to a steady value, expressed as the half-time rate constant of the energy expenditure $\left(\mathrm{TEM}_{t 1 / 2}\right)$, was $16.0 \mathrm{~min}$. For the nonobese, $\mathrm{TEM}_{t 1 / 2}$ was $14.5 \mathrm{~min}$. This $10 \%$ difference in the rate constant was statistically significant $(P \leqslant 0.05)$, and suggests a slower energy expenditure response to the meal for the obese.

Table 3 presents the TEM $_{\text {net }}(\mathrm{kJ})$ calculated as the integrated area under the TEM curve, using the fasting RMR as baseline. Even though we did not collect the total TEM $_{\text {net }}$, compared to the nonobese the obese $\mathrm{TEM}_{\text {net }}$ was still $25.8 \%$ less when expressed in absolute terms as W $(P \leqslant 0.01), 61.9 \%$ less when expressed as $\mathrm{W} \mathrm{kg}_{\mathrm{BM}}^{-1}(P \leqslant 0.01)$, and $33.2 \%$ less expressed as $\mathrm{W} \mathrm{kg}_{\mathrm{FF}}^{-1}(P \leqslant 0.01)$. When expressed relative to the meal load it was $+2.5 \%$ for the obese, and only $+3.3 \%$ for the nonobese $(P \leqslant 0.01)$. These differences between obese and nonobese subjects for short-term $\mathrm{TEM}_{\text {net }}$ are clear and impressive.

The repeat TEM measurements on 4 obese subjects revealed no differences in test/retest data for any period (Fig. 3). 

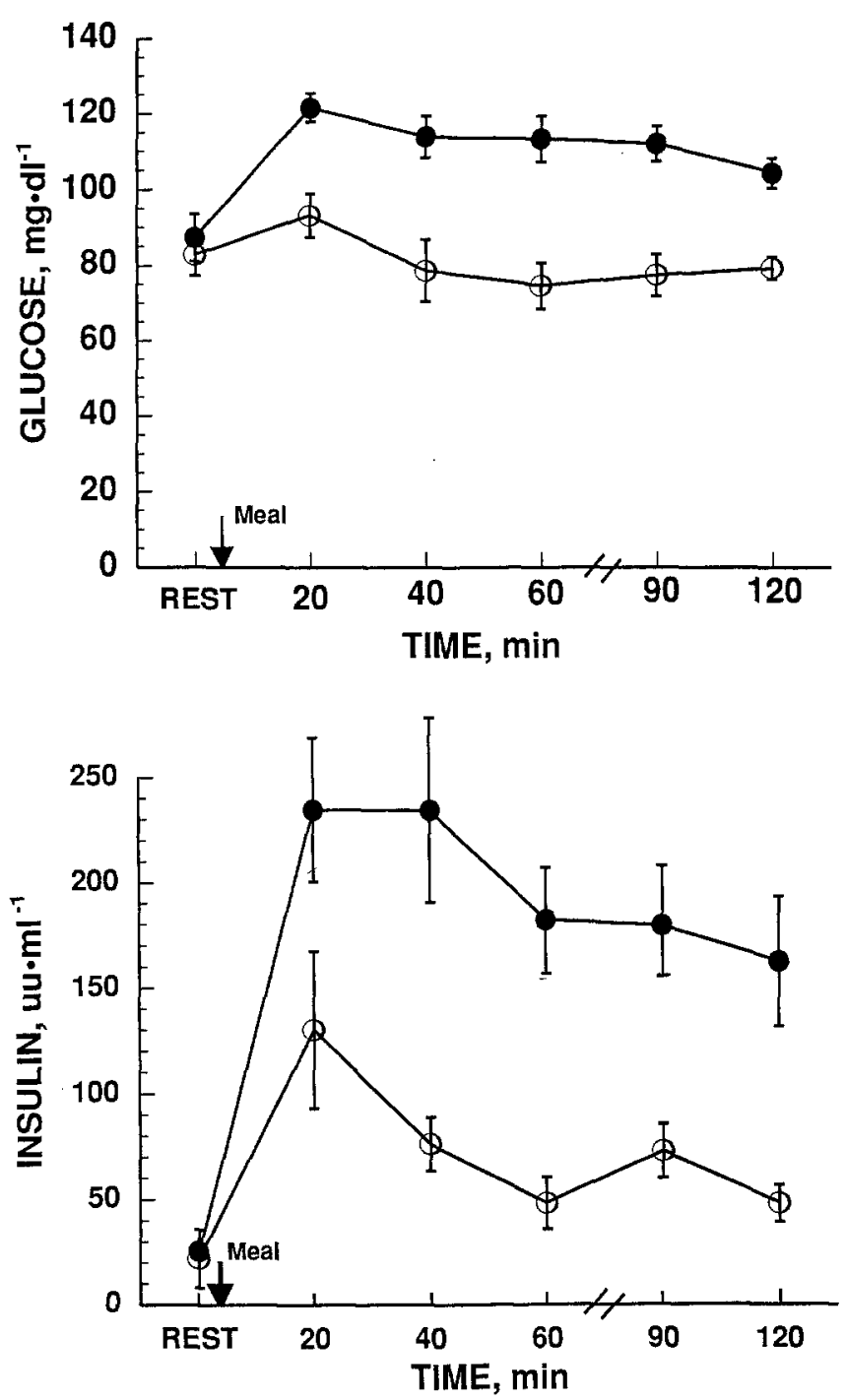

Fig. 2. Plasma glucose and insulin during rest (fasting) and following ingestion of a $3348.8 \mathrm{~kJ}$ meal. - - Obese; - O- nonobese

\section{Discussion}

This is the first study to describe a blunted short-term TEM response of obese adolescent girls. The cumulative $\mathrm{TEM}_{\text {net }}$ (Table 3 ) of the obese was significantly less by $25 \%-62 \%$, depending on the method of indexing. Also, the TEM expressed relative to the energy content of the meal, or as a percentage of the resting RMR, was less for the obese (Table 3). These data support TEM energy conservation for obese female adolescents.

The 120-min post-meal collection period was insufficient for the TEM to return to baseline, thus the cumulative TEM values are underestimates of the total TEM. Nevertheless, even with an abbreviated post-meal data collection period there were noticeable and statistical TEM differences between obese and nonobese subjects. If the post-meal energy expenditure collection had been followed to baseline, then the differences between the obese and nonobese would be further exaggerated, given the relative differences in the initial energy expenditure between the groups and the rates of decline (Fig. 3).

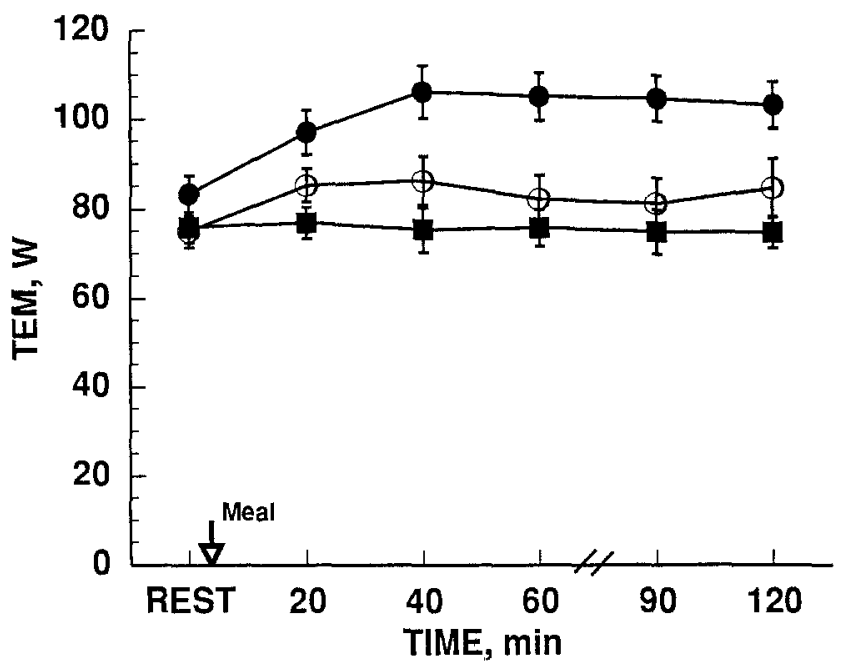

Fig. 3. Thermic effect of a meal (TEM) in obese and nonobese subjects following ingestion of a $3348.8-\mathrm{kJ}$ meal. Also shown is the TEM of 4 obese subjects following ingestion of a placebo drink. Meal ingestion resulted in a significant thermic effect for both groups $(P \leqslant 0,01)$ while the placebo effect was nonsignificant.

- O Obese; - O- nonobese; - - obese-placebo

Table 3. Cumulative net thermal energy of a meal (TEM ${ }_{\text {net }}$ ) for obese and nonobese subjects expressed in absolute and relative terms, relative to meal size and fasting metabolic rate (RMR): mean (SE)

\begin{tabular}{|c|c|c|c|c|}
\hline Variable & Obese & Nonobese & $\begin{array}{l}\text { Differ- } \\
\text { ence }(\%)\end{array}$ & $P$ \\
\hline $\operatorname{TEM}_{\text {net }}(\mathrm{kJ})^{\mathrm{a}}$ & $82.38(4.1)$ & $111.05(5.4)$ & 25.8 & $<0.001$ \\
\hline $\mathrm{TEM}_{\text {net }}(\mathrm{W} \mathrm{kg}-1) \mathrm{BM}$ & $16.0 \quad(0.66)$ & $41.8 \quad(2.2)$ & 61.7 & $<0.001$ \\
\hline $\mathrm{TEM}_{\text {net }}\left(\mathrm{W} \mathrm{kg}_{\mathrm{FF}}^{-1}\right)^{\mathrm{c}}$ & $31.3 \quad(1.3)$ & $47.5 \quad(2.2)$ & 34.1 & $<0.001$ \\
\hline $\mathrm{TEM}_{\text {net }} /$ meal $(\%)^{\mathrm{d}}$ & $2.5 \quad(0.10)$ & $3.3 \quad(0.80)$ & 25.5 & $<0.01$ \\
\hline $\mathrm{TEM}_{\text {net }} / \mathrm{RMR}(\%)^{\mathrm{e}}$ & $13.7(0.40)$ & $25.1 \quad(0.75)$ & 45.4 & $<0.001$ \\
\hline
\end{tabular}

a Total integrated area under the TEM curve minus RMR

b Total TEM relative to body mass

c Total TEM relative to fat-free mass

d $100 \times$ TEM $(\mathrm{kJ}) / \mathrm{meal}(\mathrm{kJ})$

e $100 \times$ TEM (kJ)/RMR (kJ)

Comparisons of the post-meal TEM half-times between the obese and nonobese offer a unique way to look at differences in the rates of energy expenditure that are not directly influenced by baseline and/or length-of-test effects. The limited data we present here suggest that obese female adolescents have a slower energy expenditure response immediately after the introduction of the meal. This results in reduced cumulative energy expenditure and is consistent with the data presented in Table 3.

With respect to the mechanisms for the increase in RMR following a meal, the role of insulin and sympathetic response have been recognized (Golay et al. 1982; Ravussin et al. 1983; Rothwell and Stock 1981). The observation that a blunted TEM is related to impaired glucose tolerance (Segal et al. 1990), a frequent complication of obesity, and that glucose ingestion itself may 
cause a rise in norepinephrine, raises the possibility that increases in sympathetic activity are responsible for the decreased TEM response of the obese (Welle et al. 1980). However, Shetty et al. (1981) have reported a significant TEM response in normal subjects in the absence of a rise in norepinephrine, negating the direct effects of an obese-specific sympathetic effect. More recently, Segal et al. (1990) have suggested that a reduced thermogenesis associated with insulin resistance is perhaps related to a reduced rate of nonoxidative glucose disposal, which has a greater energy cost than does glucose oxidation. The large insulin response for the obese (Fig. 2, area under the 120-min curve), suggestive of insulin resistance, is consistent with other data in the literature (Felig et al. 1983; Karam et al. 1963; Welle and Campbell 1983). This insulin resistance, in comparison to absolute levels of insulin production of the obese compared with the nonobese, may also be related to a blunted TEM by lowering the rate of glucose uptake and hence decreasing the rate of glucose storage.

A key finding of the present study was the reduced short-term TEM response of obese in comparison to nonobese adolescents (Table 3). This blunted response suggests a form of increased metabolic efficiency (energy storage per energy ingested) that would contribute to body mass gain, independent of an increased caloric intake.

Some investigators have argued that since energy intake is generally expressed in absolute mass, the TEM response should also be compared on absolute terms in order to reveal the hypermetabolism of obesity. Others have argued the opposite, suggesting that it is necessary to express metabolism relative to some estimate of metabolic size (body mass, fat-free mass, body surface area, or even $m_{\mathrm{b}}^{0.75}$ ) in order to eliminate any possible spurious effects (Kleiber 1950). In the present study we have expressed TEM not only in net terms in order to diminish the cumulative effects of any differences in the RMR baseline, but we have also expressed TEM in absolute terms, indexed to the different expressions of metabolic size.(Fig. 1, Table 3) and indexed to the size of the meal (Table 3). Our data show that, regardless of the method of expression obese female adolescents exhibit a reduced short-term TEM response compared to age-matched nonobese girls.

It might also be argued that the reason for the differences between our data and the other studies on adolescents (Bandini et al. 1989; Epstein et al. 1987; Molnar et al. 1985) is that we did not equate the energy intake. That is, since we used a meal of the same energy content for both the obese and nonobese, one would expect an exaggerated thermogenic response for the nonobese since the actual energy intake of the obese, relative to their body mass or fat-free mass, would be reduced compared to that of the nonobese. In support of using a meal with the same energy content for both obese and nonobese subjects, Segal et al. (1990) have recently demonstrated that the thermic effects of both constant and relative energy loads were significantly blunted for obese compared with nonobese men when the TEM (increment in energy expenditure) was expressed either in absolute form or as a percentage of the energy value of the food ingested. Our data concur with those of Segal et al. $(1983,1985,1990)$ in supporting a blunted TEM response in obesity and demonstrate this effect in adolescent girls.

Finally, the fasting RMR data (Fig. 1 and Table 2) are problematic. The elevated RMR is similar to the data of Felig et al. (1983). However, when the fasting RMR is expressed in relative terms ( $\mathrm{W} \mathrm{kg}_{\mathrm{BM}}^{-1}$, and $\mathrm{W} \mathrm{kg}_{\mathrm{FF}}^{-1}$ ) opposite results are observed. Whether simply dividing RMR by any body size or composition variable necessarily performs a "statistical adiposectomy" and thereby offers a more reasonable and theoretically correct expression of metabolism is debatable (Katch 1973; Katch et al. 1985, 1988a; Tanner 1949). In the present study only the non-indexed RMR values were elevated for the obese compared to the nonobese. All the other expressions of energy expenditure, both in the fasting state and following meal ingestion, were lower for the obese compared to the nonobese. This supports an energy-conservation hypothesis in adolescent obesity.

In summary, we have studied the thermogenic response to a meal of 14 obese adolescent girls. The results suggest a significantly blunted thermogenic response compared to 9 age-matched nonobese girls. These data may help explain the continued body mass gain and difficulty in maintaining energy balance experienced by obese female adolescents.

Acknowledgements. This work was supported by NIH grants Am/ HD 30989 and AM/HD 26351 and CRC grant MO1RR0042-21 (University of Michigan).

\section{References}

Bandini LG, Schoeller DA, Edwards J, et al (1989) Energy expenditure during carbohydrate overfeeding in obese and nonobese adolescents. Am J Physiol 256:E357-E367

Bauer V, Blunt K (1924) Effects of a small breakfast on the energy metabolism of children. J Biol Chem 59:77-84

Beirring E (1919) The standard metabolism of boys. Levin and Munksgaard, Copenhagen

Becque MD, Hattori K, Katch V, et al (1987) Fat patterning of adolescents. Ann Hum Biol 14:23-28.5

Becque MD, Katch V, Rocchini AP, et al (1988) Coronary risk incidence of obese adolescents: reduction by exercise plus diet intervention. Pediatrics $81: 605-612$

Blunt K, Nelson A, Olson H (1921) Basal metabolism of underweight children. J Biol Chem 49:247-262

Berson SA, Yalow RS, Glick SM, Roth J (1964) Immunoassay of protein and peptide hormones. Metabolism 13:1135-1142

Boothby K, Berkson J, Dunn H (1936) Studies of the energy of metabolism of normal individuals: a standard for the basal metabolism with a nomogram for clinical application. Am J Physiol 116:468-484

Carpenter TM (1939) Tables, factors and formulas for computing respiratory exchange and biological transformation of energy, 3rd edn. Carnegie Institute of Washington, Washington

Epstein LH, Wagner J, Nudelman S, et al (1987) The stability of resting metabolic rate and diet-induced thermogenesis in children. J Psychopharmacol Behav Assess 9:423-428

Felig P, Cunningham J, Levitt M, et al (1983) Energy expenditure in obesity in fasting and post prandial state. Am $\mathbf{J}$ Physiol $224: \mathrm{E} 45-51$ 
Golay A, Shutz Y, Meyer D, et al (1982) Glucose induced thermogenesis in nondiabetic and diabetic obese subjects. Diabetes $31: 1023,1028$

Griffiths M, Payne PR (1976) Energy expenditure in small children of obese and non-obese parents. Nature 260:698-700

Harris J, Benedict AF (1919) A biometric study of basal metabolism in man. Carnegie Inst Wash Publ 279

Huggert AS, Nixon DA (1957) Use of glucose oxidase, peroxidase, and $O$-dianisidine in determination of blood and urinary glucose. Lancet II :368-370

Jequier E, Pittet P, Goyga PH (1987) Thermic effect of glucose and thermal body insulation in lean and obese subjects: a calorimetric approach. Proc Nutr Soc 37:45-53

Jung RT, Shetty PS, James WPT (1979) Reduced thermogenesis in obesity. Nature 279:322-323

Kaplan ML, Leveille GA (1976) Calorigenic response in obese and nonobese women. Am J Clin Nutr 29:1108-1113

Karam JH, Grodsky GM, Forsham PH (1963) Excessive insulin response to glucose in obese subjects as measured by immunochemical assay. J Am Diet Assoc 12:197-204

Katch V (1973) Use of the oxygen/body weight ratio in correlational analyses: Spurious correlations and statistical considerations. Med Sci Sports 5:253-257

Katch FI, Michael ED, Horvath SM (1967) Estimation of body volume by underwater weighing: description of a simple method. J Appl Physiol 23:811-813

Katch V, Rocchini AR, Marks C, et al (1985) Basal metabolism of obese adolescents: age, gender and body composition effects. Int J Obes 9:69-76

Katch V, Becque MD, Marks C, et al (1988a) Oxygen uptake and energy output during walking of obese male and female adolescents. Am J Clin Nutr 47:26-32

Katch V, Becque MD, Marks C, et al (1988b) Basal metabolism of obese adolescents: inconsistent diet and exercise effects. Am J Clin Nutr $48: 565-569$

Katch V, Marks C, Becque MD, et al (1990) Basal metabolism of obese adolescents: evidence for energy conservation compared to normal and lean adolescents. Am J Hum Biol 2:56-63

Kleiber M (1950) Physiological meaning of regression equations. J Appl Physiol 2:417-423

McNemar Q (1969) Psychological statistics. 4th edn. J Wiley, New York

Molnar D, Varga P, Rubecz I, et al (1985) Food-induced thermogenesis in obese children. Eur J Pediatr 144:27-31

National Center for Health Statistics (1984) U. S. Public Health
Service DHHS Publication PH-85-1232, US Government Printing Office

Owen OE, Holup JL, D'Alessio DA, et al (1987) A reappraisal of the caloric requirements of men. Am J Clin Nutr 46:875-885

Ravussin E, Bogardus C, Schwartz RS, et al (1983) Thermic effect of infused glucose and insulin in man. J Clin Invest 72:893902

Rocchini AP, Katch V, Shork A, et al (1987) Insulin and blood pressure during weight loss in obese adolescents. Hypertension 10:167-173

Rocchini AP, Katch V, Anderson J, et al (1988a) Blood pressure in obese adolescents: the effects of weight loss. Pediatrics $5: 45-62$

Rothwell NJ, Stock MJ (1981) A role of insulin in the diet-induced thermogenesis of cafeteria fed rats. Metab Clin Exp 30:673678

Scholander PF (1947) Analyzer for accurate estimation of respiratory gases in one-half cubic centimeter samples. J Biol Chem $167: 235-250$

Segal KR, Gutin B (1983) Thermic effects of food and exercise in lean and obese women. Metabolism 32:581-589

Segal KR, Gutin B, Nyman AM, et al (1985) Thermic effect of food at rest, during exercise and after exercise in lean and obese men of similar body weight. J Clin Invest 76:11071112

Segal KR, Edano A, Blando L, et al (1990) Comparison of thermic effects of constant and relative caloric loads in lean and obese men. Am J Clin Nutr 51:14-21

Shetty PS, Jung RT, James WPT, et al (1981) Postprandial thermogenesis in obesity. Clin Sci 60:519-525

Siri WE (1956) Gross composition of the body. In: Lawrence JH, Tobias CA (eds) Advance in biological and medical physics: IV. Academic Press, New York, pp 239-259

Tanner JM (1949) Fallacy of per-weight and per-surface area standards and their relation to spurious correlations. J Appl Physiol 2:1-15

Waxman M, Stunkard AJ (1980) Caloric intake and expenditure of obese boys. J Pediatr 96:187-193

Welle S, Lilavivathana U, Campbell RG (1980) Increased plasma norepinephrine concentrations and metabolic rates following glucose ingestion in man. Metabolism 29:806-809

Welle SL, Campbell RG (1983) Normal thermic effect of glucose in obese women. Am J Clin Nutr 37:87-92

Wilmore JH (1969) A simplified method for determination of residual lung volumes. J Appl Physiol 27:96-100 